\title{
Influence of animal passage on haemolysin and enterotoxin production in Vibrio cholerae 01 biotype El Tor strains
}

\author{
ANJALI TIKOO, D. V. SINGH and S. C. SANYAL* \\ Department of Microbiology, Institute of Medical Sciences, Banaras Hindu University, Varanasi 221 005, India
}

\begin{abstract}
Summary. Of 43 strains of Vibrio cholerae O1 biotype El Tor isolated over a span of almost three decades (1964 1990) from stools of children and adults with diarrhoea (25 isolates) and from sewage (three) and water from the river Ganges (15) examined for production of haemolysin and its correlation with enterotoxin production, 17 isolates showed haemolysis. The majority of isolates (26), including $68 \%$ of diarrhoeal and $50 \%$ of environmental origin, were non-haemolytic. The titre of haemolysin produced was $4-16 \mathrm{HU} / \mathrm{ml}$, irrespective of the source of isolation. Haemolytic strains caused significantly more fluid accumulation than the non-haemolytic strains in the rabbit ileal loop (RIL) test. Twenty nine (67.4) $\mathrm{V}$. cholerae biotype El Tor isolates-all the haemolytic and most (61.5\%) of the non-haemolytic isolates tested-caused fluid accumulation. The remaining non-haemolytic strains that caused little or no accumulation of fluid did so after one to four consecutive passage(s) through RIL without change in haemolytic character; these strains required more consecutive passage through rabbit gut to show haemolysis. All these strains reverted to their original non-haemolytic character on repeated subculture or on storage in the laboratory but continued to show enterotoxic activity. The present study indicated that $\mathrm{El} \mathrm{Tor} \mathrm{haemolysin} \mathrm{is} \mathrm{not} \mathrm{responsible} \mathrm{for}$ fluid accumulation in rabbit gut.
\end{abstract}

\section{Introduction}

Vibrio cholerae $\mathrm{O} 1$ biotype $\mathrm{El}$ Tor is the causative agent of the current seventh cholera pandemic which started in Celebes island in $1961 .{ }^{1}$ Unlike strains of the classical biotype, which are non-haemolytic, strains of El Tor produce and secrete a haemolysin into the culture medium. This feature has been used to distinguish the two biotypes. However, haemolytic activity did not always correlate with the El Tor biotype and many strains were reported to be non-haemolytic. ${ }^{2}$ This discrepancy has generated confusion in the biotype designation of $V$. cholerae $\mathrm{O} 1$ isolates. More recent reports suggest that the haemolysin produced by El Tor strains is identical to that of V.cholerae nonO1. ${ }^{3-5}$ It has also been suggested that the El Tor-like haemolysin of $V$. cholerae non-O1 can produce fluid accumulation in adult rabbit ileal loops. ${ }^{6}$ Alm et al. ${ }^{7}$ indicated that the haemolysin may be enterotoxic because fluid accumulation in rabbit ileal loops was not observed when the whole haemolytic determinant was deleted from the chromosome of a non-toxigenic but diarrhoea-producing strain of El Tor biotype.

The present study of isolates of $V$. cholerae $\mathrm{O} 1$ biotype $\mathrm{El}$ Tor from diarrhoea and water was under-

Received 1 June 1993; revised version accepted 20 Sept. 1993. * Correspondence should be sent to Dr S. C. Sanyal. taken to test the production of haemolysin and enterotoxin, to examine any change in haemolytic character after passage through rabbit ileal loops and to look for any correlation between production of haemolysin and enterotoxic activity.

\section{Materials and methods}

\section{Bacterial strains}

Forty-three isolates of $V$. cholerae $\mathrm{O} 1$ biotype $\mathrm{El}$ Tor isolated during a period of almost three decades (1964-1990) from children and adults with diarrhoea (25), from sewage (3) and from the river Ganges (15) were obtained from our laboratory stock and included in the study. The number of isolates from each decade were two isolates from the period 1964-1969, 11 from 1970-1979, 23 from 1980-1989 and seven isolates from 1990. The strains were identified according to the criteria of Finkelstein and Mukerjee ${ }^{8}$ and Barua and Gomez $^{9}$ and further characterised by the methods recommended by the WHO. ${ }^{10}$

\section{Detection of haemolysis}

Preliminary testing for haemolysis by $V$. cholerae $\mathrm{O} 1$ biotype El Tor was performed by inoculating 4-5-h growths of each organism in Brain Heart Infusion 
Table I. Haemolytic activity of $V$. cholerae $\mathrm{Ol}$ biotype El Tor strains before and after passage through rabbit ileal loops

\begin{tabular}{|c|c|c|c|c|}
\hline $\begin{array}{l}\text { Year of isolation, } \\
\text { source and } \\
\text { haemolytic } \\
\text { character }\end{array}$ & $\begin{array}{c}\text { Number } \\
\text { tested } \\
\text { before } \\
\text { passage }\end{array}$ & $\begin{array}{c}\text { Haemolysin } \\
\text { production } \\
(\mathrm{HU} / \mathrm{ml})\end{array}$ & $\begin{array}{c}\text { Number } \\
\text { tested } \\
\text { after } \\
\text { passage* }\end{array}$ & $\begin{array}{c}\text { Haemolysin } \\
\text { production } \\
(\mathrm{HU} / \mathrm{ml})\end{array}$ \\
\hline \multicolumn{4}{|l|}{$1964-69$} & \\
\hline Non-haemolytic & 2 & NT & 2 & $4-16$ \\
\hline \multicolumn{5}{|l|}{$1970-79$} \\
\hline Haemolytic & 2 & $4-16$ & 0 & \\
\hline Non-haemolytic & 7 & NT & 6 & $4-16$ \\
\hline \multicolumn{5}{|l|}{ Environmental } \\
\hline Haemolytic & 1 & 4 & 0 & 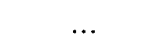 \\
\hline Non-haemolytic & 1 & NT & 1 & 8 \\
\hline \multicolumn{5}{|l|}{$1980-89$} \\
\hline \multicolumn{5}{|l|}{ Diarrhoeal } \\
\hline Haemolytic & 3 & $4-16$ & 0 & \\
\hline Non-haemolytic & 4 & NT & 2 & $8-16$ \\
\hline \multicolumn{5}{|l|}{ Environmental } \\
\hline Haemolytic & 8 & $4-16$ & 0 & \\
\hline Non-haemolytic & 8 & NT & 8 & $4-16$ \\
\hline \multicolumn{5}{|l|}{1990} \\
\hline \multicolumn{5}{|l|}{ Diarrhoeal } \\
\hline Haemolytic & 3 & $4-16$ & 0 & \\
\hline Non-haemolytic & 4 & NT & 3 & $4-16$ \\
\hline
\end{tabular}

NT, not tested.

*Non-haemolytic strains tested only after passage.

Table II. Haemolytic character and enterotoxicity of Vibrio cholerae $\mathrm{O} 1$ biotype El Tor

\begin{tabular}{|c|c|c|c|c|c|}
\hline $\begin{array}{c}\text { Source and } \\
\text { haemolytic } \\
\text { character }\end{array}$ & $\begin{array}{l}\text { Number of } \\
\text { strains } \\
\text { tested }\end{array}$ & $\begin{array}{c}\text { Number } \\
\text { showing fluid } \\
\text { accumulation } \\
\text { before passage }\end{array}$ & $\begin{array}{c}\text { Fluid } \\
\text { accumulation } \\
\text { (ml/cm of gut) }\end{array}$ & $\begin{array}{c}\text { Number } \\
\text { showing fluid } \\
\text { accumulation } \\
\text { after passage* }\end{array}$ & $\begin{array}{c}\text { Fluid } \\
\text { accumulation } \\
\text { (ml/cm of gut) }\end{array}$ \\
\hline \multicolumn{6}{|l|}{ Diarrhoeal } \\
\hline Haemolytic & 8 & 6 & $1 \cdot 0-1 \cdot 3$ & 2 & NT \\
\hline Non-haemolytic & 17 & 10 & $0.4-0.6$ & 7 & $0.4-1.5$ \\
\hline \multicolumn{6}{|l|}{ Environmental } \\
\hline Haemolytic & 9 & 7 & $0 \cdot 7-1 \cdot 1$ & 2 & NT \\
\hline Non-haemolytic & 9 & 6 & $0.3-0.5$ & 3 & $0 \cdot 3-1 \cdot 0$ \\
\hline Positive control ${ }^{\dagger}$ & $\ldots$ & $\ldots$ & $1 \cdot 0-1 \cdot 4$ & $\ldots$ & $1 \cdot 0-1 \cdot 4$ \\
\hline Negative control $\ddagger$ & $\ldots$ & $\ldots$ & $0-0$ & $\cdots$ & $0-0$ \\
\hline
\end{tabular}

NT, not tested.

* These strains were tested only after passage.

$\dagger$ BHIB culture of $V$. cholerae strain 569B.

$\ddagger$ BHIB.

Broth (BHIB; Difco) on to sheep blood $5 \%$ agar. After incubation for $24 \mathrm{~h}$ at $37^{\circ} \mathrm{C}$, the blood agar plates were examined for haemolysis around the colony.

\section{Preparation of culture filtrates for haemolysin and enterotoxin production}

Culture filtrates of the isolates of $V$. cholerae $\mathrm{O} 1$ biotype El Tor which were shown to be haemolytic were prepared by the method of Richardson et al. ${ }^{11}$ Briefly, BHIB (10 ml) contained in 50-ml conical flasks was inoculated with five or six colonies grown overnight on blood agar plates. The flasks were incubated at $37^{\circ} \mathrm{C}$ in a shaking water bath for $16-18 \mathrm{~h}$ with
$80-120$ oscillations $/ \mathrm{min}$. The cultures were centrifuged at $22000 \mathrm{~g}$ for $20 \mathrm{~min}$ at $4^{\circ} \mathrm{C}$ and supernates were filtered through a membrane filter (Millipore; $0.45 \mu \mathrm{m}$ ) and stored at $4^{\circ} \mathrm{C}$. These culture filtrates (CF) were used for haemolysin and enterotoxin assays.

\section{Titration of haemolysin}

The production of haemolysin by each strain of $V$. cholerae $\mathrm{O} 1$ biotype $\mathrm{El}$ Tor was confirmed by the method of Smith ${ }^{12}$ and modified by Rennie and Arbuthnott ${ }^{13}$ as described by Singh and Sanyal. ${ }^{14}$ Briefly, sheep erythrocytes (SRBC) were washed three times in isotonic saline and a $2 \% \mathrm{v} / \mathrm{v}$ suspension was prepared in $0.04 \mathrm{M}$ phosphate-buffered saline (PBS, 
$\mathrm{pH} 7 \cdot 4$ ). To determine haemolytic activity, $0.5 \mathrm{ml}$ of two-fold serial dilutions of $\mathrm{CF}$ of each strain was mixed with an equal volume of SRBC $2 \% \mathrm{v} / \mathrm{v}$ suspension, incubated at $37^{\circ} \mathrm{C}$ for $2 \mathrm{~h}$ in a water bath and left at $4^{\circ} \mathrm{C}$ for $12 \mathrm{~h}$. The lysed portion was diluted four-fold with sterile normal saline and the optical density at $540 \mathrm{~nm}$ was measured in a colorimeter. Standardisation of the erythrocyte suspension was done by lysis of $0.5 \mathrm{ml}$ of SRBC $2 \% \mathrm{v} / \mathrm{v}$ suspension with a few crystals of saponin. An optical density of 0.5 at $540 \mathrm{~nm}$ was considered to indicate a standardised SRBC $2 \% \mathrm{v} / \mathrm{v}$. The negative control was $0.5 \mathrm{ml}$ of saline instead of CF. One Haemolytic Unit (HU) was defined as the amount of CF that caused $50 \%$ haemolysis under the experimental conditions.

\section{Ileal loop test}

Whole cells and culture filtrates of the 43 strains of $V$. cholerae $\mathrm{O} 1$ biotype $\mathrm{El}$ Tor were tested in adult albino rabbits by the method of De and Chatterje for enterotoxin detection. ${ }^{15}$ Briefly, bacteria grown in BHIB for $3 \mathrm{~h}$ were diluted 10 -fold in the same medium and $1 \mathrm{ml}$ containing $10^{5}-10^{6} \mathrm{cfu}$ was inoculated into a rabbit ileal loop (RIL). A BHIB culture of toxigenic strain $569 \mathrm{~B}$ of $V$. cholerae $\mathrm{O} 1$ was used as a positive control and unseeded BHIB as a negative control. CF $(1 \mathrm{ml})$ was tested in the same way. Each test was done in three rabbits. Rabbits were killed after $18 \mathrm{~h}$.

\section{Passage through rabbit ileal loops}

Strains of $V$. cholerae $\mathrm{O} 1 \mathrm{El}$ Tor that showed no haemolysis or caused no fluid accumulation in the initial test were passaged through RILs according to the method of Sanyal et al ${ }^{16,17}$ Briefly, each strain was cultured aseptically from a RIL on nutrient agar and incubated overnight; five or six colonies were then inoculated into BHIB, incubated for $3 \mathrm{~h}$, and $1 \mathrm{ml}$ of diluted culture was inoculated again into the RIL. The process was continued until a positive response was obtained.

\section{Results}

Seventeen of the 43 isolates of $V$. cholerae $\mathrm{O} 1$ biotype El Tor produced haemolysis on sheep blood $5 \%$ agar. The majority of isolates (26), including $68 \%$ of diarrhoeal and $50 \%$ of environmental isolates, were non-haemolytic irrespective of the year of isolation (table I).

CFs of those isolates of $V$. cholerae $\mathrm{O} 1$ biotype $\mathrm{El}$ Tor that caused haemolysis on sheep blood $5 \%$ agar

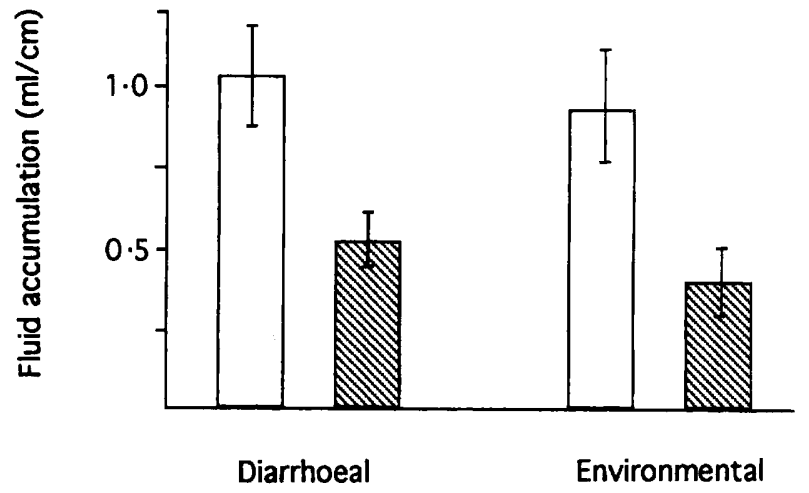

Figure. Enterotoxicity of haemolytic $(\square)$ and non-haemolytic $(\mathbb{\mathbb { N }})$ strains of $V$. cholerae Ol biotype El Tor without animal passage: diarrhoeal (13 strains); water (13 strains); bar, SD.

Table III. Influence of animal passage on fluid accumulation and change in haemolytic character in $V$. cholerae $\mathrm{O} 1$ biotype $\mathrm{E} 1$ Tor strains

\begin{tabular}{|c|c|c|c|c|c|c|}
\hline \multirow{2}{*}{ Strain no. } & \multirow{2}{*}{$\begin{array}{l}\text { Haemolytic } \\
\text { character }\end{array}$} & \multicolumn{5}{|c|}{$\begin{array}{c}\text { Fluid accumulation }(\mathrm{ml} / \mathrm{cm}) \text { after } \\
\text { passage no. }\end{array}$} \\
\hline & & 0 & 1 & 2 & 3 & 4 \\
\hline D-3440-2 & Non-haemolytic & 0.6 & 0.9 & $1 \cdot 0$ & $1 \cdot 2$ & 1.5 \\
\hline D-1824 & Non-haemolytic & $0 \cdot 5$ & 0.9 & $1 \cdot 0$ & $1 \cdot 2$ & $1 \cdot 4$ \\
\hline D-941 & Non-haemolytic & ND & ND & ND & 1.0 & $1 \cdot 3$ \\
\hline D-13 & Non-haemolytic & ND & ND & ND & ND & 1.5 \\
\hline D-1970 & Non-haemolytic & 0.4 & 0.8 & $0.9 *$ & 1.0 & $1 \cdot 2$ \\
\hline D-4164 & Non-haemolytic & ND & 0.4 & $0.9 *$ & $1 \cdot 4$ & $1 \cdot 5$ \\
\hline D-1798-2B & Non-haemolytic & 0.5 & 0.7 & $0.9 *$ & 1.0 & $1 \cdot 4$ \\
\hline D-32 & Non-haemolytic & 0.6 & 0.9 & $1 \cdot 0^{*}$ & $1 \cdot 2$ & 1.4 \\
\hline D-IDH-2 & Haemolytic & $1 \cdot 3$ & 1.5 & NT & NT & NT \\
\hline D-NICD-1 & Haemolytic & $1 \cdot 0$ & $1 \cdot 2$ & NT & NT & NT \\
\hline D-1140-S & Haemolytic & 0.9 & $1 \cdot 2$ & NT & NT & NT \\
\hline W-1659-B & Non-haemolytic & ND & 0.4 & 0.7 & 1.0 & $1 \cdot 2^{*}$ \\
\hline W-1986-DG & Non-haemolytic & ND & $0 \cdot 3$ & $0.5^{*}$ & 0.9 & $1 \cdot 2$ \\
\hline W-1986-CG & Non-haemolytic & $0 \cdot 3$ & 0.8 & $1 \cdot 2$ & $1.5 *$ & 1.6 \\
\hline W-1980-20 & Non-haemolytic & $0 \cdot 4$ & $0 \cdot 7$ & $0.8^{*}$ & 1.0 & 1.3 \\
\hline W-1988-10T & Non-haemolytic & 0.5 & $0.9 *$ & $1 \cdot 2$ & $1 \cdot 3$ & 1.5 \\
\hline W-1988-11T & Non-haemolytic & $0 \cdot 3$ & $0.8^{*}$ & 1.0 & 1.2 & 1.5 \\
\hline W-1044-SW & Haemolytic & $0 \cdot 7$ & $1 \cdot 0$ & NT & NT & NT \\
\hline W-1988-7T & Haemolytic & $1 \cdot 1$ & $1 \cdot 3$ & NT & NT & NT \\
\hline
\end{tabular}

D, diarrhoeal; W, water; ND, not detected; NT, not tested.

* Change to haemolysis detected. 
Table IV. Enhancement of titres of haemolysin of $V$. cholerae O1 biotype E1 Tor strains after passage through rabbit ileal loops

\begin{tabular}{|c|c|c|c|c|c|c|}
\hline \multirow{2}{*}{ Strain no. } & \multirow{2}{*}{$\begin{array}{l}\text { Haemolytic } \\
\text { character }\end{array}$} & \multicolumn{5}{|c|}{$\begin{array}{c}\text { Haemolysin titres }(\mathrm{HU} / \mathrm{ml}) \text { after } \\
\text { passage no. }\end{array}$} \\
\hline & & 0 & 1 & 2 & 3 & 4 \\
\hline D-3440-2 & Non-haemolytic & - $^{*}$ & ND & ND & ND & ND \\
\hline D-1824 & Non-haemolytic & _* & ND & ND & ND & ND \\
\hline D-941 & Non-haemolytic & - & - & - & ND* & ND \\
\hline D-13 & Non-haemolytic & - & - & - & - & ND* \\
\hline D-1970 & Non-haemolytic & $\ldots *$ & ND & 16 & 64 & 128 \\
\hline D-4164 & Non-haemolytic & - & $\mathrm{ND}^{*}$ & 8 & 32 & 128 \\
\hline D-1798-2B & Non-haemolytic & —* & ND & 16 & 32 & 128 \\
\hline D-32 & Non-haemolytic & -* & ND & 16 & 32 & 128 \\
\hline D-IDH-2 & Haemolytic & $4^{*}$ & 16 & - & - & - \\
\hline D-NICD-1 & Haemolytic & $16^{*}$ & 32 & - & - & - \\
\hline D-1140-S & Haemolytic & $4^{*}$ & 16 & - & - & - \\
\hline W-1659-B & Non-haemolytic & - & ND* & ND & ND & 16 \\
\hline W-1986-DG & Non-haemolytic & - & $\mathrm{ND}^{*}$ & 8 & 16 & 128 \\
\hline W-1986-CG & Non-haemolytic & —* & ND & ND & 16 & 64 \\
\hline W-1980-20 & Non-haemolytic & —* & ND & 4 & 8 & 32 \\
\hline W-1988-10T & Non-haemolytic & -* & 8 & 16 & - & - \\
\hline W-1988-11T & Non-haemolytic & _* & 16 & 32 & - & - \\
\hline W-1044-SW & Haemolytic & $8 *$ & 16 & - & - & - \\
\hline W-1988-7T & Haemolytic & $4^{*}$ & 8 & - & - & - \\
\hline
\end{tabular}

D, diarrhoeal; W, water; -, not tested; ND, not detected.

* Enterotoxin produced.

plates, also caused lysis of sheep erythrocytes in $2 \%$ suspension. The titres of haemolytic activity were 4-16 HU/ml. No difference in the titre of haemolytic activity was observed with regard to either source or year of isolation. However, there was strain to strain variation in the titres of haemolysin production (table I).

Cultures and CFs of $29(67.4 \%)$ of the 43 strains tested caused fluid accumulation during the initial test (table II). Thirteen of the 17 haemolytic strains caused fluid accumulation before passage, the remaining four became enterotoxic after passage. However, $61.5 \%$ of the non-haemolytic isolates also showed enterotoxic activity in the RILs. The remaining non-haemolytic strains that initially showed little enterotoxicity caused fluid accumulation after one to four consecutive passages through RILs (table II).

Haemolytic strains caused significantly more fluid accumulation than the non-haemolytic strains, irrespective of source of isolation $(\mathrm{p}<0.05$, Student's $t$ test) (figure).

Fourteen non-haemolytic and five haemolytic strains of $V$. cholerae O1 biotype El Tor tested by consecutive passages in RILs caused a marked increase in fluid accumulation after each passage (table III). The non-haemolytic enterotoxigenic isolates became haemolytic after one to three consecutive passages through rabbit gut. The titres of haemolysin produced increased after each passage (table IV). However, on repeated subcultures or on storage in the laboratory, all these isolates reverted to their original nonhaemolytic character, but showed enterotoxic activity. The four non-haemolytic isolates of diarrhoeal origin did not show haemolysis even after four consecutive passages but showed a secretory response (table IV).

\section{Discussion}

There have been reports that many isolates of $V$. cholerae $\mathrm{O} 1$ biotype $\mathrm{El}$ Tor may not produce haemolysin. ${ }^{2,18-20}$ The data from this study also indicate that most of the strains of biotype El Tor in this series, which were isolated over a span of almost three decades, showed no haemolysis in the initial tests. However, most of these non-haemolytic strains became haemolytic on sheep blood $5 \%$ agar plates after one to four serial passages through RILs. Moreover, the titres of haemolysin in CFs also increased after each passage. This phenomenon may be explained by the genetic evidence that sequences homologous to the haemolysin gene are present in both haemolytic and non-haemolytic strains of $V$. cholerae $\mathrm{O} 1$ biotype $\mathrm{El}$ Tor, but are probably not expressed in non-haemolytic isolates. ${ }^{21}$

Several workers have suggested that the haemolysin produced by the haemolytic strains of $V$. cholerae $\mathrm{O} 1$ biotype $\mathrm{El}$ Tor is responsible for their enterotoxic activity. ${ }^{6,7,22}$ However, the results of the present study indicate that a significant number of non-haemolytic strains of $V$. cholerae $\mathrm{O} 1$ biotype $\mathrm{El}$ Tor caused fluid accumulation in the initial tests. This indicates that the haemolysins may not be responsible for enterotoxic activity; the secretory response might have been initiated by enterotoxin. This observation is further strengthened by the fact that four non-haemolytic strains caused fluid accumulation even though they did not produce haemolysin after four consecutive passages through RILs. However, it was observed that the haemolytic strains caused significantly more fluid accumulation than the non-haemolytic isolates, irrespective of their source of isolation. These observ- 
ations suggest that the enterotoxic potential is not confined to the haemolytic strains but non-haemolytic isolates also possess this property to a lesser extent. However, the probability that the expressed haemolysin gene may increase the enterotoxic activity of $\mathrm{El}$ Tor strains, as observed in Aeromonas spp., cannot be ruled out. ${ }^{14}$

Ichinose et al. ${ }^{6}$ reported that El Tor-like haemolysin produced by $V$. cholerae non-O1, which was unrelated to cholera toxin $(\mathrm{CT})$, showed enterotoxic activity and occasionally caused fluid accumulation with mucus and blood in RILs. They also suggested that CT genenegative $V$. cholerae $\mathrm{O} 1$ strains probably produced an El Tor-like haemolysin factor responsible for diarrhoea. However, the present study indicated that strains of $V$. cholerae $\mathrm{O} 1$ biotype $\mathrm{El}$ Tor are enterotoxic irrespective of their haemolytic character and the accumulated fluid in the rabbit gut was without blood and mucus, like that of experimental cholera. Furthermore, the toxin produced by CT gene-negative $V$. cholerae $\mathrm{O} 1$ strains was shown to be enterotoxic but non-haemolytic. ${ }^{23}$ Thus, the data from this study clearly indicate that El Tor haemolysin is not responsible for fluid accumulation in rabbit gut and that enterotoxin is the most likely factor responsible for the enterotoxic activity of these strains and also of the classical biotype.

The strains of $V$. cholerae $\mathrm{O} 1 \mathrm{El}$ Tor that failed to produce enterotoxin in the initial tests caused fluid accumulation after one to four consecutive passages through rabbit gut, suggesting that all the strains of $V$. cholerae $\mathrm{O} 1$ biotype El Tor are potentially enterotoxigenic irrespective of their haemolytic character and source of isolation. Similar observations regarding the effect of passage through the gut of a susceptible host were demonstrated in our earlier studies with $V$. cholerae $\mathrm{O}^{17}$ and also with many other organisms such as $V$. cholerae non-01, ${ }^{24} V$. fluvialis, ${ }^{25} V$. mimicus, ${ }^{16,26}$ Aeromonas spp., ${ }^{14,27-30}$ Plesiomonas shigelloides $^{31}$ and Klebsiella pneumoniae. ${ }^{32}$ Furthermore, it is known that the so-called hypertoxigenic strain 569B of $V$. cholerae $\mathrm{O} 1$ also requires passage through rabbit gut for enhancement of toxin pro-

\section{References}

1. Kamal AM. The seventh pandemic of cholera. In: Barua D, Burrows W (eds) Cholera. Philadelphia, W. B. Saunders Company. 1974: 1-14.

2. Barrett TJ, Blake PA. Epidemiological usefulness of changes in hemolytic activity of Vibrio cholerae biotype El Tor during the seventh pandemic. $J$ Clin Microbiol $1981 ; 13: 126-129$.

3. Honda T, Finkelstein RA. Purification and characterization of a hemolysin produced by Vibrio cholerae biotype El Tor: another toxic substance produced by cholera vibrios. Infect Immun 1979; 26: 1020-1027.

4. Yamamoto K, Al-Omani M, Honda T, Takeda Y, Miwatani T. Non-O1 Vibrio cholerae haemolysin: purification, partial characterization and immunological relatedness to El Tor haemolysin. Infect Immun 1984; 45: 192-196.

5. Yamamoto $\mathrm{K}$, Ichinose $\mathrm{Y}$, Nakasone $\mathrm{M}$ et al. Identity of haemolysins produced by Vibrio cholerae non-O1 and $V$. cholerae O1, biotype El Tor. Infect Immun 1986; 51: 927-931.

6. Ichinose Y, Yamamoto K, Nakasone $\mathrm{N}$ et al. Enterotoxicity of duction; a mechanism of repression-derepression controlling the expression of toxin gene may account for this phenomenon..$^{33}$ It appears that expression of a toxin gene in a bacterial strain is a means of its adaptation to a particular micro-environment such as occurs with $V$. cholerae. ${ }^{33}$

There have been reports of loss of the ability to produce haemolysin as a result of subculture in the laboratory as well as disappearance of the haemolytic trait from epidemic biotype El Tor strains. ${ }^{8,34}$ It was noted in this study that most toxigenic non-haemolytic strains of $V$. cholerae $\mathrm{O} 1$ biotype $\mathrm{El}$ Tor produced a haemolysin after one to three consecutive passages through rabbit gut. These observations may also indicate that the phenomenon of repression and derepression may operate in the case of the haemolysin gene and that the rabbit gut probably provides a micro-environment for its expression. Further evidence is provided by the reversion of these strains to their original non-haemolytic character on repeated subcultures or prolonged preservation in the laboratory. A similar phenomenon of repressionderepression controlling the expression of the haemolysin gene has been reported in Aeromonas spp. ${ }^{14,29} \mathrm{It}$ is possible that the four isolates of toxigenic $V$. cholerae O1 biotype El Tor that showed no haemolysis even after four consecutive passages through rabbit gut might have become haemolytic on further passage. It is also possible that these strains did not possess the haemolysin gene.

This study indicates that most strains of $V$. cholerae O1 biotype El Tor, irrespective of source of isolation, are potentially enterotoxigenic and haemolytic and that enterotoxin is the factor most likely to be responsible for their enterotoxic activity. Passage through the gut of a susceptible host may control the expression of the genes responsible for enterotoxin and haemolysin production.

The study was supported in part by the Council of Scientific and Industrial Research, New Delhi. A.T. and D.V.S. were the recipients of fellowships from the Council of Scientific and Industrial Research. The authors are grateful for the secretarial assistance of Mr D. Venu Gopal.

El Tor-like haemolysin of non-O1 Vibrio cholerae. Infect Immun 1987; 55: 1090-1093.

7. Alm RA, Stroeher UH, Manning PA. Extracellular proteins of Vibrio cholerae: nucleotide sequence of the structural gene (hlyA) for the haemolysin of the haemolytic El Tor strain of 017 and characterization of the hlyA mutation in the non-haemolytic classical strain 569B. Mol Microbiol 1988; 2: $481-488$.

8. Finkelstein RA, Mukerjee S. Haemagglutination: a rapid method for differentiating Vibrio cholerae and El Tor vibrios. Proc Soc Exp Biol Med 1963; 112: 355-359.

9. Barua D, Gomez CZ. Observation of some tests commonly employed for the characterization of El Tor vibrios. Bull World Health Organ 1967; 37: 800-803.

10. WHO. Manual for laboratory investigations of acute enteric infections. Geneva, WHO. CDD/83.3 1987.

11. Richardson K, Michalski J, Kaper JB. Haemolysin production and cloning of two hemolysin determinants from classical Vibrio cholerae. Infect Immun 1986; 54: 415-420.

12. Smith HW. Haemolysins of Escherichia coli. J Pathol Bacteriol 1963; 85: 197-211. 
13. Rennie RP, Arbuthnott JP. Partial characterisation of Escherichia coli haemolysin. J Med Microbiol 1974; 7: 179-188.

14. Singh DV, Sanyal SC. Production of haemolysis and its correlation with enterotoxicity in Aeromonas spp. $J$ Med Microbiol 1992; 37: 262-267.

15. De SN, Chatterje DN. Experimental study of mechanism of action of Vibrio cholerae on intestinal mucous membrane. $J$ Pathol Bacteriol 1953; 66: 559-562.

16. Sanyal SC, Huq MI, Neogy PKB, Alam K, Kabir MI, Rahaman AS. Experimental studies on the pathogenicity of Vibrio mimicus strains isolated in Bangladesh. Aust J Exp Biol Med Sci 1984; 62: 515-521.

17. Sanyal SC, Neogi PKB, Alam K, Huq MI, Al-Mahmud KA. A new enterotoxin produced by Vibrio cholerae O1. $J$ Diarrhoeal Dis Res 1984; 2: 3-12.

18. de Moore CE. A non-haemolytic vibrio. Trop Geogr Med 1963; 15: 97-107.

19. Finkelstein RA. Preselection of hemolytic variants of El Tor vibrios. J Bacteriol 1966; 92: 513-514.

20. Gallut J. La septieme pandemic cholerique. Bull Soc Pathol Exot Filiales 1971; 64: 551-560.

21. Brown MH, Manning PA. Haemolysin gene of Vibrio cholerae: presence of homologous DNA in non-haemolytic $\mathrm{O} 1$ and haemolytic non O1 strains. FEMS Microbiol Lett 1985; 30: 197-201.

22. Yamamoto $\mathrm{K}$, Ichinose $\mathrm{Y}$, Shinagawa $\mathrm{H}$ et al. Two step processing for activation of the cytolysin/hemolysin of Vibrio cholerae $\mathrm{O} 1$ biotype $\mathrm{El}$ Tor: nucleotide sequence of the structural gene (hlyA) and characterization of the processed products. Infect Immun 1990; 58: 4106-4116.

23. Saha S. Studies on new cholera toxin. PhD Thesis, Banaras Hindu University, Varanasi, India. 1989.
24. Shanker P, Agarwal RK, Sanyal SC. Experimental studies on enteropathogenicity of Vibrio cholerae serotype other than O1. Zentralbl Bakteriol Mikrobiol Hyg (A) 1982; 252: 514-524.

25. Sanyal SC, Agarwal RK, Annapurna E, Lee JV. Enterotoxicity of group F vibrios. Jpn J Med Sci Biol 1980; 33: 217-222.

26. Sanyal SC, Huq MI, Neogi PKB et al. Vibrio mimicus as an aetiologic agent of diarrhoea and its pathogenesis. Indian $J$ Med Microbiol 1983; 1 : 1-12.

27. Annapurna E, Sanyal SC. Studies on enteropathogenicity of Aeromonas hydrophila in an experimental model. Indian $J$ Prev Soc Med 1975; 6: 234-237.

28. Annapurna E, Sanyal SC. Enterotoxicity of Aeromonas hydrophila. J Med Microbiol 1977; 10: 317-323.

29. Singh DV, Sanyal SC. Haemolysin and enterotoxin production by Aeromonas caviae isolated from diarrhoeal patients, fish and environment. J Diarrhoeal Dis Res 1992; 10: 16-20.

30. Singh DV, Sanyal SC. Enterotoxicity of clinical and environmental isolates of Aeromonas spp. J Med Microbiol 1992; 36: $269-272$.

31. Sanyal SC, Saraswathi B, Sharma P. Enteropathogenicity of Plesiomonas shigelloides. J Med Microbiol 1980; 13: 401-409.

32. Raychaudhury A, Agarwal RK, Sanyal SC. Enteropathogenicity of Klebsiella pneumoniae strains isolated from stools of diarrhoeal patients and other clinical specimens: an experimental study. Zentralbl Bakteriol Mikrobiol Hyg (A) 1984 ; 258 : 94-103.

33. Singh SJ, Sanyal SC. Enterotoxicity of the so-called NAG vibrios. Ann Soc Belg Med Trop 1978; 58: 133-140.

34. Roy C, Mukerjee S, Tanamal SJW. Haemolytic and nonhaemolytic El Tor vibrios. Ann Biochem Exp Med 1963; 23: $553-558$ 